\title{
Analysis and Development of Triangular Gasket Diagonal Slot Embedded Fractal Patch Antenna for Multiband Wireless Applications
}

\author{
MUHAMMAD KHALID*, AND KAMRAN RAZA* \\ RECEIVED ON 10.08.2017 ACCEPTED ON 03.05.2019
}

\begin{abstract}
This paper presents novel reduced size diagonal slot embedded Triangular Gasket fractal patch antenna for multiband wireless applications. The diagonal slot geometry is embedded in triangular patch antenna for initial size reduction of the basic cell and further miniaturization is achieved by fractalization of the cell upto third order. Three frequency resonances of 2.4, 6.5 and 9.23 GHz are optimized for WiFi, WiMAX and WLAN (Wireless Local Area Network) applications in the S, C and X frequency bands. Size reduction upto 55.32 and $\mathbf{8 0 . 7 4 \%}$ is achieved in terms of whole antenna area and copper cladding remaining respectively in comparison to triangular patch antenna. Antenna 3D (Three-Dimensional) modeling, simulation and optimization for the desired BW (Bandwidth) and gain requirements are done in HFSS (High Frequency Structure Simulator) and CST (Computer Simulation Technology). Effects of embedding diagonal slot in the basic triangular cell is analyzed in terms of the diagonal slot length and width with corresponding frequency response variations. Microstrip feed line dimensions and ground plane separation from the radiating top layer is optimized for achieving acceptable BWs less than -10 dB for the desired multiple resonances. E-field, H-field, current density and surface current plots are presented to verify the radiations for multiband wireless applications. Proposed slot embedded fractal radiator is fabricated and measured frequency responses and gain patterns are demonstrated in comparison with simulated results for verification of the concept.
\end{abstract}

Key Words: Gasket Fractal, Patch Antenna, Size Reduction, Multib and Miniaturization.

\section{INTRODUCTION}

$\mathrm{F}$ ractals with many different geometrical configurations are used for improving gain as well as impedance characteristics of antennas. With the development of wireless systems, multiband frequency bands provide operational frequencies for various applications. Several fractal designs have been investigated for providing enhanced antenna performance characteristics in recent years. Sierpinski fractal geometries can be combined with Minkowski fractals in dielectric resonator antenna configuration for size reduction purposes [1]. Overall array size and inter element mutual coupling is reduced by using fractal 
based EBG (Electromagnetic Band Gap) decoupling rows placed between the array elements [2], with insertion loss improvement of $13 \mathrm{~dB}$ is attained by compact structure as well as embedding of slots at the ground plane. Hexagonal shaped fractal antenna is used for providing wideband by combining the patch radiating element with Sierpinski square shapes [3], where stable omnidirectional radiation patterns are attained over the wide range of BW.

Sierpinski triangles can also be used to provide radiation for WLAN and WiMAX applications by providing multiport antenna structure with different auxiliary and main ports [4], and enabling time reversal propagation for obtaining enhanced received signal strength in comparison to the transmitted signal strength. Hilbert fractal antennas are used for detecting various partial discharge types in oil insulated system applications [5], where different antenna structures are selected with noisy conditions based on the level of detected signal to noise ratios. Koch Island fractal configuration is numerically and experimentally analyzed and employed in microstrip patch antennas for miniaturization purposes achieving directive patterns having localized current distributions due to higher order modes [6]. Sierpinski fractal antenna with triangular configuration can be used for thermal transfer applications by using diode circuits for switching between ISM (Industrial Scientific and Medical) and UHF (Ultra High Frequency) frequency bands [7]. Dual band operation using two parasitic patches for $\mathrm{BW}$ enhancement is presented in [8]. RLC (Resistor Inductor Capacitor) resonators electrical circuit model is presented. Antenna is optimized using method of moment commercial code for achieving 4.7 and $6.8 \% \mathrm{BW}$ for the two resonant bands. The radiation in first and second resonance bands is demonstrated using current distribution plots for the top and bottom layer patches respectively. Different ratios of the Sierpinski fractal radiator are analyzed for providing improved input impedance in [9]. Use of pentagonal fractal geometry with embedded first order Koch geometry for miniaturization and multiband radiations is shown in [10]. Sierpinski fractals can also be used along with the dielectric resonator configured antenna for providing dual band radiation characteristics for WiMAX and WLAN applications [11].

Sierpinski fractal carpet antennas can be used for providing improved radiations pattern due to unwanted surface wave cancellation techniques by embedding EBG structures at the ground plane and analyzing the characteristics by using combination of segmentation and modified contour integral methods [12]. Here the impedance $\mathrm{BW}$ of the fractal radiator is improved upto $9 \%$ in comparison to traditional fractal antennas with impedance $\mathrm{BW}$ of $2 \%$. Circular polarization is achieved in microstrip patch antenna by combining layer wise Peano and square structures [13], with multiband characteristics and some degree of miniaturization also achieved, where the microstrip antenna is fed through electromagnetic coupling. Generalized Sierpinski antenna is presented with log periodic characteristics implemented through Pascal triangle [14]. Various fractal element radiator antennas are designed for USB (Universal Serial Bus) dongle, mobile and energy harvesting applications [15-19].

This paper presents the novel methodology for miniaturizing the triangle patch antenna by embedding optimized diagonal slot geometry configuration in the center of the patch antenna and then fractalizing upto third order in a Triangular gasket fashion thus further miniaturizing upto $55.32 \%$ in terms of the overall size of the radiator and $80.74 \%$ in terms of the copper cladding remaining and producing desired frequency bands for 
wireless communication applications. In addition to the miniaturization, the proposed design also simultaneously exhibits enhanced antenna characteristics of multiband resonances at $\mathrm{S}, \mathrm{C}$, and $\mathrm{X}$ bands as well as directional patterns with increased gain due to the patch antenna configuration of the proposed third order slot embedded triangular gasket fractal.

\section{ANTENNADESIGNAND ANALYSIS}

The directional diagonal slot embedded Triangular Gasket fractal patch antenna is designed for radiating in several frequency bands for wireless communication applications. The triangular patch radiator is embedded with optimized diagonal slot for miniaturization in the zero order geometry of the fractal configuration and further miniaturization and multiband characteristics are achieved by fractalizing the diagonal slot embedded triangular patch upto third order. The proposed third order fractal antenna configuration labeled HFSS 3D model is demonstrated in Fig. 1. The top layer consists of the third order diagonal slot embedded triangular gasket fractal radiator, fed by microstrip transmission line.

The HFSS 3D labeled model of triangular patch antenna is shown in Fig. 2(a), demonstrating the configuration

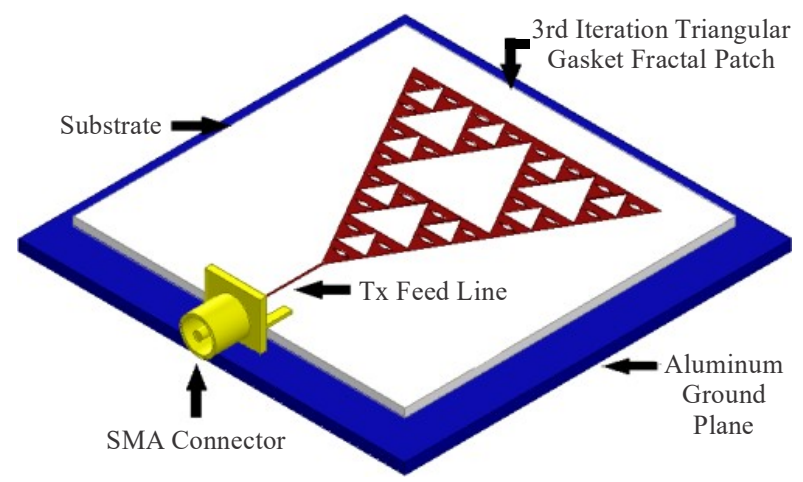

FIG. 1. PROPOSED 3D ARCHITECTURE OF THIRD ORDER DIAGONAL SLOT EMBEDDED TRIANGULAR GASKET FRACTAL PATCH ANTENNA LABELED PERSPECTIVE VIEW and placement of triangular patch antenna, substrate, aluminum ground plane and SMA(Sub Miniature Version A) connector along with the transmission feed line serving the purpose of feeding the patch antenna. Dimension drawing of triangular printed patch radiator is demonstrated in Fig. 2(b), with the side of each triangle patch antenna optimized at $67.34 \mathrm{~mm}$ for the radiations of the antenna at first resonant frequency for WiFi applications with its response centered at $2.4 \mathrm{GHz}$.

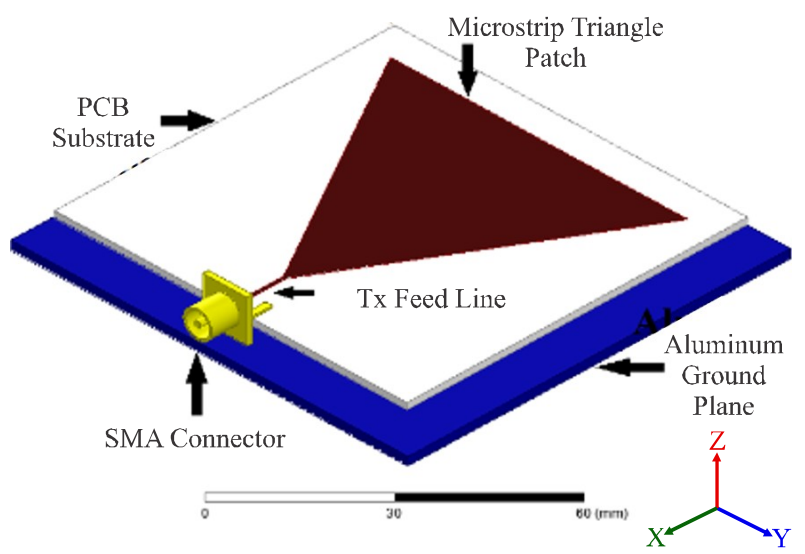

(a) LABELED PERSPECTIVE VIEW

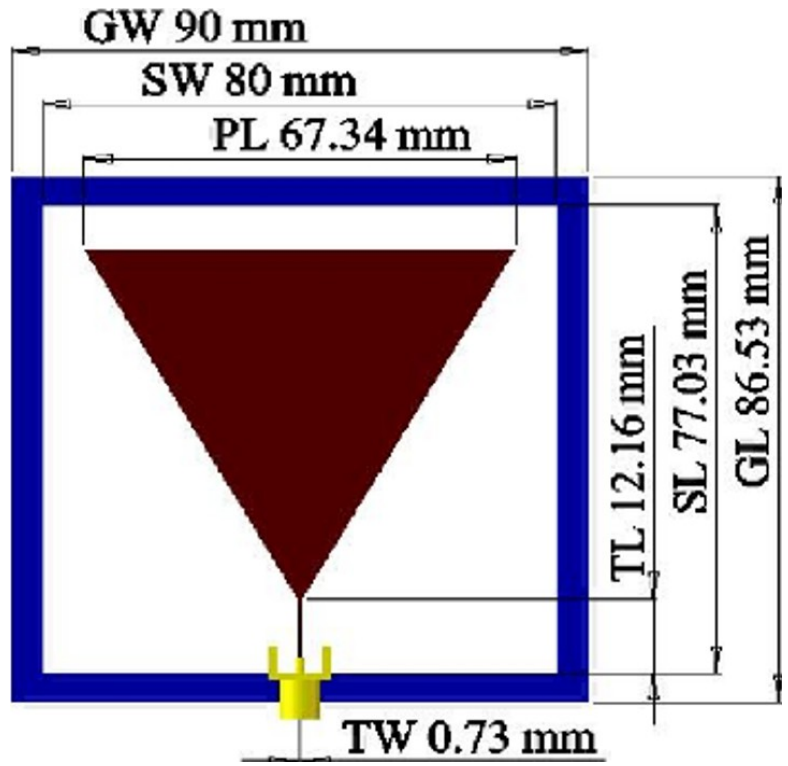

(b) DIMENSIONS TOP VIEW

FIG. 2. 3D MODEL OF TRIANGULAR PATCH ANTENNA

Mehran University Research Journal of Engineering \& Technology, Volume 38, No. 3, July, 2019 [p-ISSN: 0254-7821, e-ISSN: 2413-7219] 
Dimensions of substrate along with bottom ground plane are optimized in accordance with the top layer triangular patch radiator dimensions. The width and length of the transformer is optimized at 0.73 and $12.16 \mathrm{~mm}$ respectively for the accurate transformation of the edge impedance of the triangular printed patch radiator in accordance with $50 \Omega$ SMA connector.

HFSS 3D labeled model and dimension drawing of the basic cell diagonal slot embedded triangle patch antenna is shown in Fig. 3(a-b) respectively. Diagonal slot optimized configuration with the length and width of 34 and $10 \mathrm{~mm}$ respectively is embedded in the triangular patch having each side of $67.3 \mathrm{~mm}$ for size reduction of the triangular patch antenna, while all other dimensions of the substrate, aluminum ground plane and transmission feed line are kept same as designed for the radiation of triangular patch antenna at $2.4 \mathrm{GHz}$.

The embedded diagonal slot dimensions are optimized for achieving maximum frequency down shift and optimal impedance matching. The effects of embedding the diagonal slot geometry in the triangular patch antenna are demonstrated in Fig. 4. As the dimension of the diagonal slot structure is increased, the resonant frequency of the triangular patch antenna shifts downwards. Starting from $-26 \mathrm{~dB}$ at $2.4 \mathrm{GHz}$ with the length and width of the diagonal slot at $10 \mathrm{~mm}$, the frequency tends to shift on $-8 \mathrm{~dB}$ at $2.1 \mathrm{GHz}$. With the increase in area of the diagonal slot, the frequency keeps on shifting to lower points, while also degrading the impedance matching. Optimized diagonal slot width and length of 10 and $34 \mathrm{~mm}$ respectively is selected, with the frequency response of $-11 \mathrm{~dB}$ at $2.2 \mathrm{GHz}$, hence a $200 \mathrm{MHz}$ downwards frequency shift without compromising on the efficiency of the triangular patch antenna.

In order to shift the frequency upwards back to $2.4 \mathrm{GHz}$, the size of the antenna is to be reduced, hence signifying the size reduction in the basic cell of the proposed fractal configuration. Corresponding to the different frequency responses shown in Fig. 4, configurations of diagonal slot embedded triangular printed patch radiator are demonstrated in Fig. 5(a), with embedded diagonal slot having minimum length and width of 10 and $10 \mathrm{~mm}$ respectively and maximum length and width of 34 and $20.6 \mathrm{~mm}$ respectively.

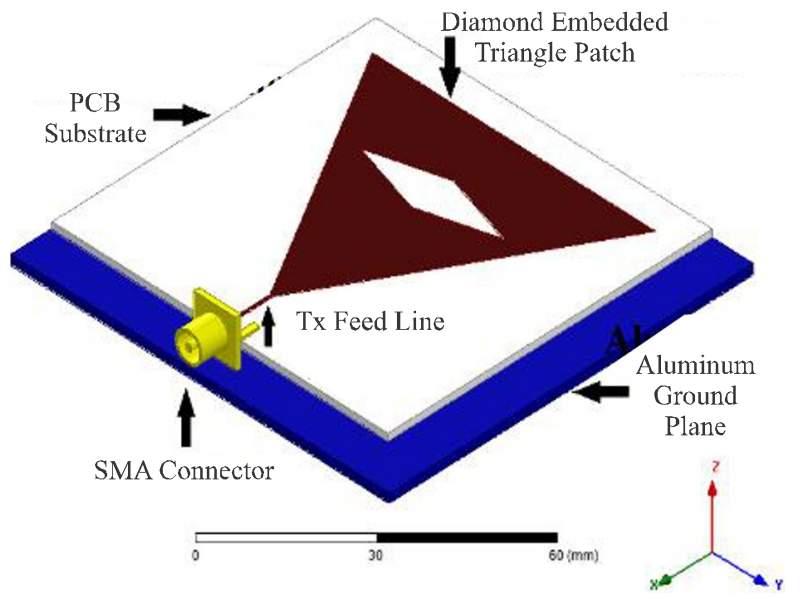

(a) LABELED PERSPECTIVE VIEW

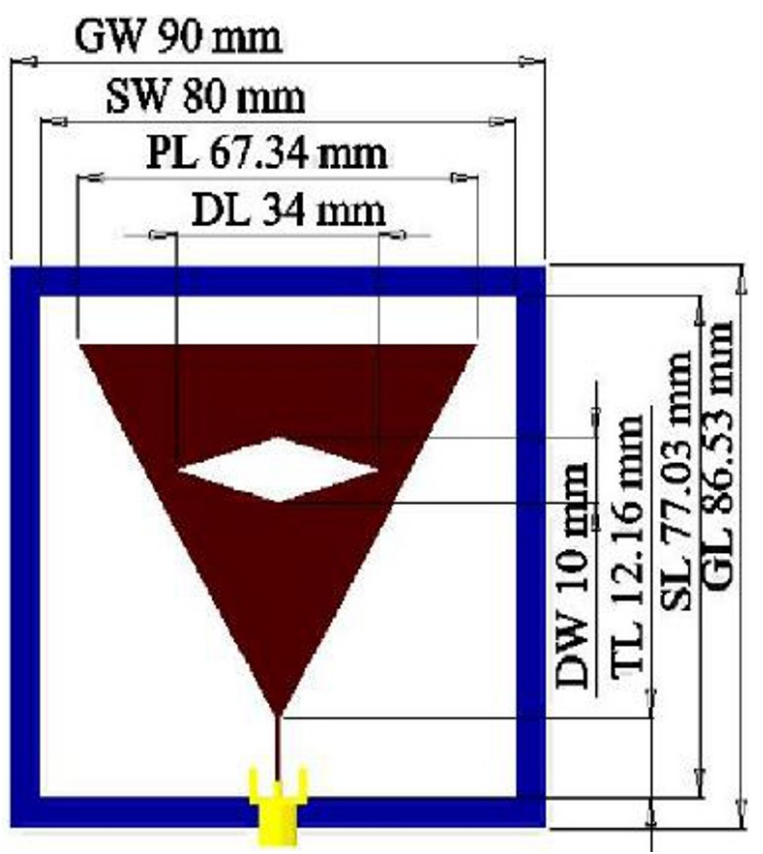

(b) DIMENSIONS TOP VIEW

FIG. 3. 3D MODEL OF DIAGONAL SLOT EMBEDDED TRIANGULAR PATCH ANTENNA

Mehran University Research Journal of Engineering \& Technology, Volume 38, No. 3, July, 2019 [p-ISSN: 0254-7821, e-ISSN: 2413-7219] 
The fractalization process of proposed diagonal slot embedded Triangular Gasket fractal printed patch radiator is shown in Fig. 5(b). Triangle printed patch radiator is designed to radiate for WiFi applications as shown in Fig. 5 (b), with the frequency response centered at $2.4 \mathrm{GHz}$. The size reduction in the triangular patch is achieved by embedding diagonal slot geometry in the triangular printed patch radiator as depicted in Fig. 5(b). First iteration of the Triangular Gasket diagonal slot embedded fractal printed antenna as illustrated in Fig. 5(b), is achieved by growing scaled down diagonal slot embedded triangular basic cell, with a scaling factor of 0.51 with respect to the basic cell, at the three vertices of the basic cell. The first order fractal geometry consists of three scaled diagonal slot embedded patches. In the first order fractal geometry the embedded diagonal slots are scaled down with a scaling factor of 0.51 with respect to the diagonal slot embedded in the basic cell of the proposed fractal geometry.

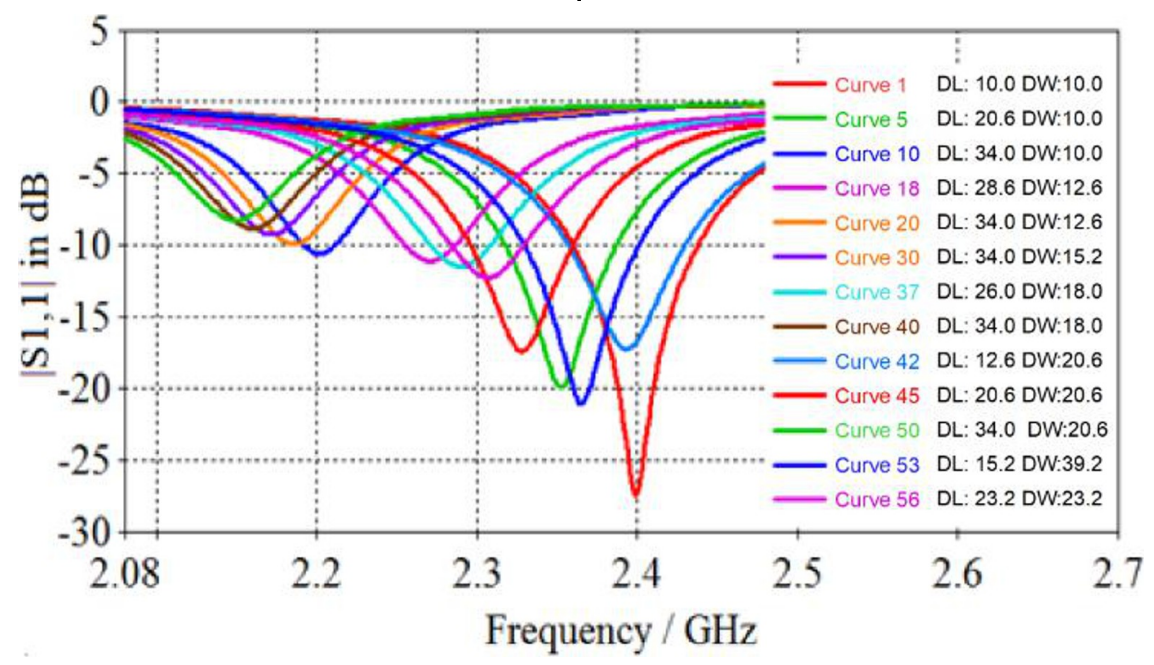

FIG. 4. EFFECTS OF EMBEDDING DIFFERENT DIAGONAL SLOT GEOMETRIES ON FREQUENCY RESPONSE OF TRIANGULAR PATCH ANTENNA

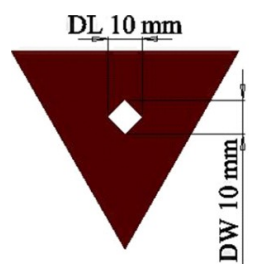

DL $34 \mathrm{~mm}$

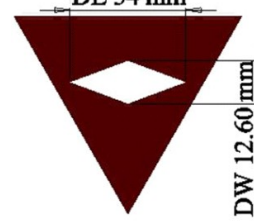

DL $12.60 \mathrm{~mm}$

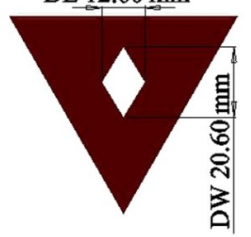

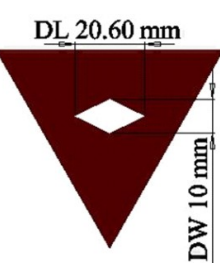

DL $34 \mathrm{~mm}$

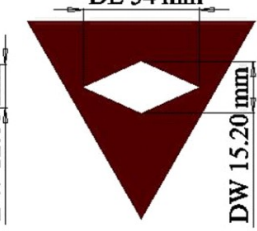

DL $34 \mathrm{~mm}$

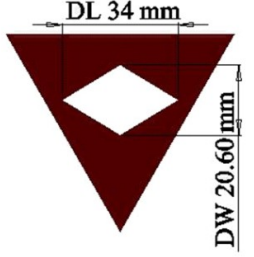

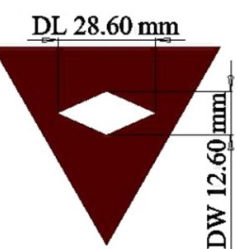

DL $26 \mathrm{~mm}$

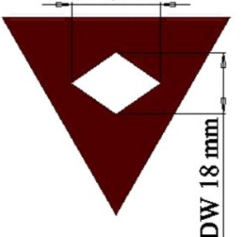

DL $15.20 \mathrm{~mm}$

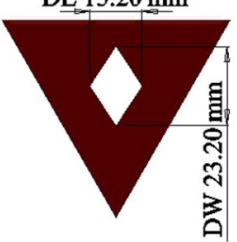

FIG. 5(a). VARIOUS DIMENSIONS OF EMBEDDED DIAGONAL SLOT GEOMETRY IN THE TRIANGULAR PATCH ANTENNA
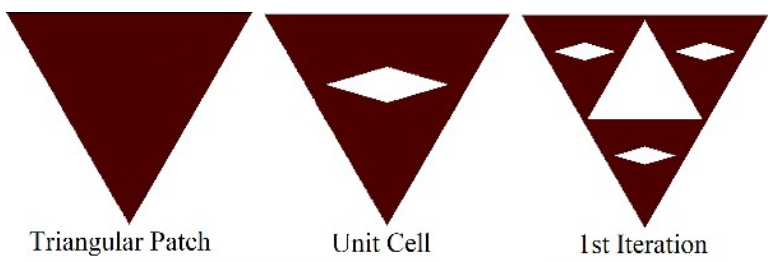

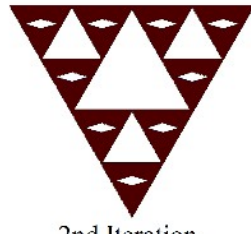

2nd Itcration Cell 1st Iteration

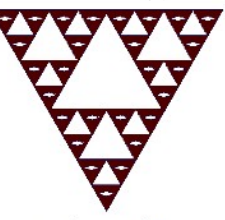

3rd Itcration

FIG. 5(b). PROPOSED DIAGONAL SLOT EMBEDDED TRIANGULAR GASKET FRACTALIZATION WITH TRIANGULAR PATCH, UNIT CELL, FIRST ITERATION, SECOND ITERATION, AND THIRD ITERATION

Mehran University Research Journal of Engineering \& Technology, Volume 38, No. 3, July, 2019 [p-ISSN: 0254-7821, e-ISSN: 2413-7219] 
The second order diagonal slot embedded triangular fractal geometry consists of nine diagonal slot embedded triangular patches as exemplified in Fig. 5(b), which are scaled at the scaling factor of 0.51 with respect to the diagonal slot embedded triangles of first order fractal geometry and scaled at the scaling factor of 0.2601 with respect to the diagonal slot triangle of the basic cell. The embedded nine diagonal slots at the center of the nine diagonal slot triangles of the second order are scaled at the scaling factor of 0.51 and 0.2601 with respect to the embedded diagonal slots of the first order and basic cell geometries respectively.

Third iteration of the diagonal slot embedded triangular gasket patch is depicted in Fig. 5(b). Proposed fractal consists of twenty-seven small scaled diagonal slot embedded triangles, where the triangles and embedded slots are scaled at the scaling factor of $0.51,0.2601$ and 0.1326 with respect to second order diagonal slot embedded triangles, first order diagonal slot embedded triangles and basic unit cell diagonal slot embedded triangle respectively.

Effects of varying ground plane separation from the third order proposed diagonal slot embedded Gasket Triangle fractal antenna are shown in Fig. 6. Starting from ground plane separation of $1.11 \mathrm{~mm}$, parametric analysis is done upto the ground plane separation of $10 \mathrm{~mm}$. With the ground plane separation of $1.11 \mathrm{~mm}$, the first resonant frequency band of the proposed antenna is at $2.23 \mathrm{GHz}$ at $-9.105 \mathrm{~dB}$. At the ground plane separation of $4.44 \mathrm{~mm}$ the frequency of the first harmonic moves to $2.54 \mathrm{GHz}$ at $-16.55 \mathrm{~dB}$, thus increasing the ground plane separation improves the impedance matching of resonant frequency band while also shifting the bands upwards.

Further increasing the height improves the impedance matching of the proposed fractal patch antenna upto 7.77 $\mathrm{mm}$ with the frequency response of $2.53 \mathrm{GHz}$ at $-29.78 \mathrm{~dB}$ and then impedance matching starts to degrade with the frequency response of $2.5 \mathrm{GHz}$ at $-16.85 \mathrm{~dB}$ for the ground plane separation of $10 \mathrm{~mm}$. Thus increasing the ground plane separation from $4.44 \mathrm{~mm}$, impedance matching in the first resonant frequency band can be optimized without affecting the center frequency of the band. Bandwidth of the first resonant frequency band also tends to remain constant with the increase in ground plane separation from the proposed fractal patch antenna from 4.44-10 mm.

The ground plane spacing with the radiating patch fractal element is optimized for best posible resonant bands as

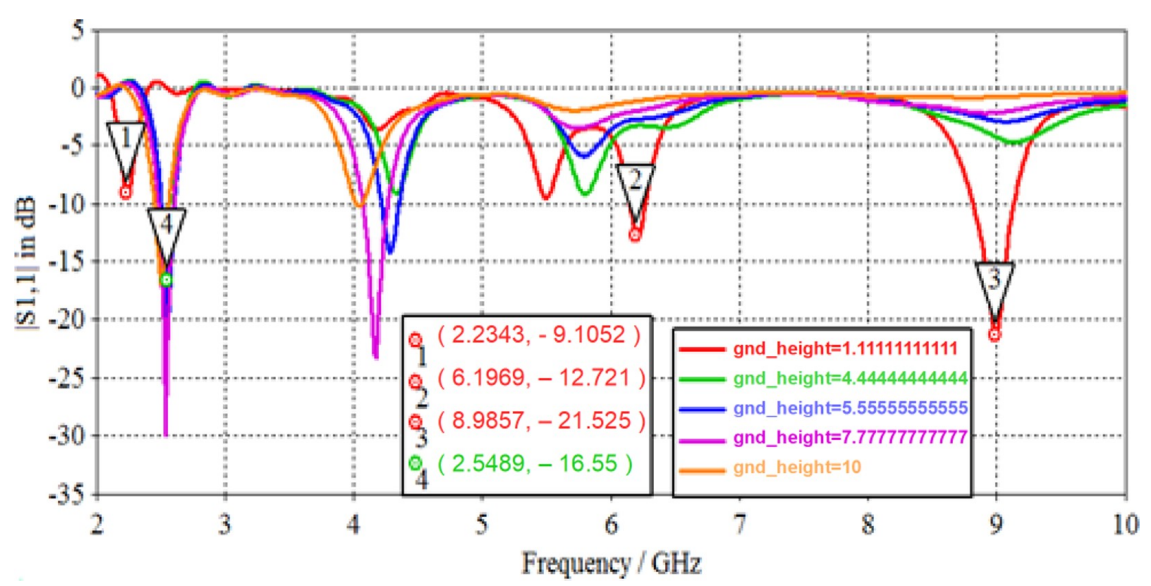

FIG. 6. VARIATIONS OF RESONANT FREQUENCY BANDS WITH RESPECT TO THE GROUND PLANE SEPERATION OF THE PROPOSED FRACTAL PATCH ANTENNA

Mehran University Research Journal of Engineering \& Technology, Volume 38, No. 3, July, 2019 [p-ISSN: 0254-7821, e-ISSN: 2413-7219] 
shown in Fig. 6. With the ground plane separation of 1.1 $\mathrm{mm}$ from the diagonal slot Triangular Gasket fractal patch radiator, the second band frequency responses are 5.49 $\mathrm{GHz}$ at $-9.52 \mathrm{~dB}$ and $6.21 \mathrm{GHz}$ at $-12.94 \mathrm{~dB}$, whereas the third resonance is optimized for $8.99 \mathrm{GHz}$ at $-21.53 \mathrm{~dB}$. Also with the ground plane seperation of $4.44 \mathrm{~mm}$ the second band frequency response is increased to $5.81 \mathrm{GHz}$ at $-9.16 \mathrm{~dB}$ and the third resonance is optimized for 9.11 $\mathrm{GHz}$ at $-4.71 \mathrm{~dB}$.

Increasing the ground plane separation from the patch antenna from $1.11 \mathrm{~mm}$, the impedance matching and bandwidth of the first resonant band increases, whereas the impedance matching for the second and third frequency bands tends to keep on degrading. As with the ground plane separation of $10 \mathrm{~mm}$, the frequency responses of the second and third bands are supressed. Hence optimal value of ground plane separation from the fractal patch radiator is selected to be around $2 \mathrm{~mm}$ for radiations of the diagonal slot embedded Triangular Gasket fractal patch radiator in S, C and X frequency bands.

Effects of varying microstrip feed length and width on the desired frequency bands of proposed third iteration diagonal slot Triangular Gasket fractal patch antenna are shown in Fig. 7(a-b) respectively. As seen from Fig. 7(a), the length of the transmission microstrip line is varied from 2-20 $\mathrm{mm}$. First resonance of proposed fractal patch antenna is $2.715 \mathrm{GHz}$ at -3.093 . By increasing the length of the feed line at 10 and $20 \mathrm{~mm}$, the frequency of the fractal patch antenna is shifted to $2.49 \mathrm{GHz}$ at $-6.2 \mathrm{~dB}$ and $2.32 \mathrm{GHz}$ at $-9.55 \mathrm{~dB}$ respectively. Thus increasing the length of the line shifts the first resonant frequency of the proposed fractal patch antenna downwards, while also improving the impedance matching of the antenna.

Second and third frequency resonances are also effected with the variations in feed line length, with the frequency of the second and third resonant band to be $6.31 \mathrm{GHz}$ at $-6.21 \mathrm{~dB}$ and $9.67 \mathrm{GHz}$ at $-11.92 \mathrm{~dB}$ respectively at feed line length of $2 \mathrm{~mm}$. Increasing the length at $10 \mathrm{~mm}$ shifts the second resonant band of the proposed fractal patch antenna to $6.04 \mathrm{GHz}$ at $-8.45 \mathrm{~dB}$. Further increasing the feed length to $14 \mathrm{~mm}$, the proposed fractal antenna starts resonating at frequencies $5.8 \mathrm{GHz}$ at $-22.56 \mathrm{~dB}$ and 6.52 $\mathrm{GHz}$ at $-28.14 \mathrm{~dB}$ in $\mathrm{C}$ Band, where the third resonant frequency band is shifted to $9.38 \mathrm{GHz}$ at $-9.98 \mathrm{~dB}$. Thus increasing the feed line length improves the BW of the resonances in $\mathrm{C}$ and $\mathrm{X}$ frequency bands while shifting frequency points downwards.

Increasing the feed line length upto $20 \mathrm{~mm}$ shifts the third resonant frequency band to $8.034 \mathrm{GHz}$ at $-15.31 \mathrm{~dB}$ and in second frequency band of $\mathrm{C}$ Band the first frequency point is shifted down to $5.306 \mathrm{GHz}$ at $-18.718 \mathrm{~dB}$ and the second frequnecy point is shifted to $6.26 \mathrm{GHz}$ at -4.709 $\mathrm{dB}$. Hence increasing the line length upto $20 \mathrm{~mm}$ shifts the frequency responses in the $\mathrm{C}$ and $\mathrm{X}$ Bands downwards, while also degrading the impedance matching of the second resonant frequency of the $\mathrm{C}$ Band. Therefore, considering the radiation of slot embedded Triangular Gasket fractal patch radiator in three frequency bands of S, C and X simultaneously, feed line length of around $14 \mathrm{~mm}$ is selected for optimum BW and impedance matching in the desired frequency bands.

Variations of microstrip feed line width and its effects on the frequency responses are demonstrated in Fig. 7(b). Effects of frequency points in the desired bands are optimized by varying the feed line width from 0.1-1.5 mm. Starting from feed line width of $0.1 \mathrm{~mm}$, corresponding frequency response in the $\mathrm{S}$ Band is $2.404 \mathrm{GHz}$ at -11.53 $\mathrm{dB}$ with the $\mathrm{BW}$ of $51.8 \mathrm{MHz}$ with impedance bandwith $\mathrm{S}_{11}$ less than $-10 \mathrm{~dB}$ is from $2.38-2.434 \mathrm{GHz}$. 
Increasing the feed line width to $0.25 \mathrm{~mm}$ produces almost identical frequency response at the first frequency band, whereas increasing line width to $0.566 \mathrm{~mm}$ shifts the frequency point to $2.41 \mathrm{GHz}$ at $-7.36 \mathrm{~dB}$. Further increasing the line width to $1.03 \mathrm{~mm}$ and then to $1.5 \mathrm{~mm}$ shifts the resonant frequency point to $2.4207 \mathrm{GHz}$ at $-5.91 \mathrm{~dB}$ and $2.428 \mathrm{GHz}$ at $-4.26 \mathrm{~dB}$ respectively, therefore increasing the line width from $0.25 \mathrm{~mm}$ onwards shifts the first resonant point of the proposed fractal patch antenna upwards while also degrading the impedance matching of the frequency band.

Variations in the feed line with exciting the fractal patch antenna also effects the second and third resonant bands. With the line width of $0.1 \mathrm{~mm}$, the two resonances produced in the $\mathrm{C}$ band are at $5.73 \mathrm{GHz}$ at $-17.71 \mathrm{~dB}$ and $6.45 \mathrm{GHz}$ at $-17.39 \mathrm{~dB}$, while frequency response in the $\mathrm{X}$ band is $9.25 \mathrm{GHz}$ at $-10.63 \mathrm{~dB}$. At microstrip feed line width of $0.56 \mathrm{~mm}$ the first resonant point of the $\mathrm{C}$ band is shifted at $5.7 \mathrm{GHz}$ and second band is optimized at $6.46 \mathrm{GHz}$, improving the $\mathrm{BW}$ of the first resonance, while second frequency point is degraded on increasing the width from $0.1 \mathrm{~mm}$ upto $0.56 \mathrm{~mm}$. Frequency point of third band is tuned to $9.185 \mathrm{GHz}$ with improved impedance matching. Increasing the feed line width to $1.03 \mathrm{~mm}$ and then to 1.5 $\mathrm{mm}$ shifts the frequencies to $5.68 \mathrm{GHz}$ at $-21.85 \mathrm{~dB}$ and $6.49 \mathrm{GHz}$ at $-16.567 \mathrm{~dB}$ for the $\mathrm{C}$ band and $9.051 \mathrm{GHz}$ at $15.15 \mathrm{~dB}$ for the $\mathrm{X}$ band and $5.69 \mathrm{GHz}$ at $-24.69 \mathrm{~dB}, 6.507$ $\mathrm{GHz}$ at $-18.62 \mathrm{~dB}$ and $9.02 \mathrm{GHz}$ at $-19.48 \mathrm{~dB}$

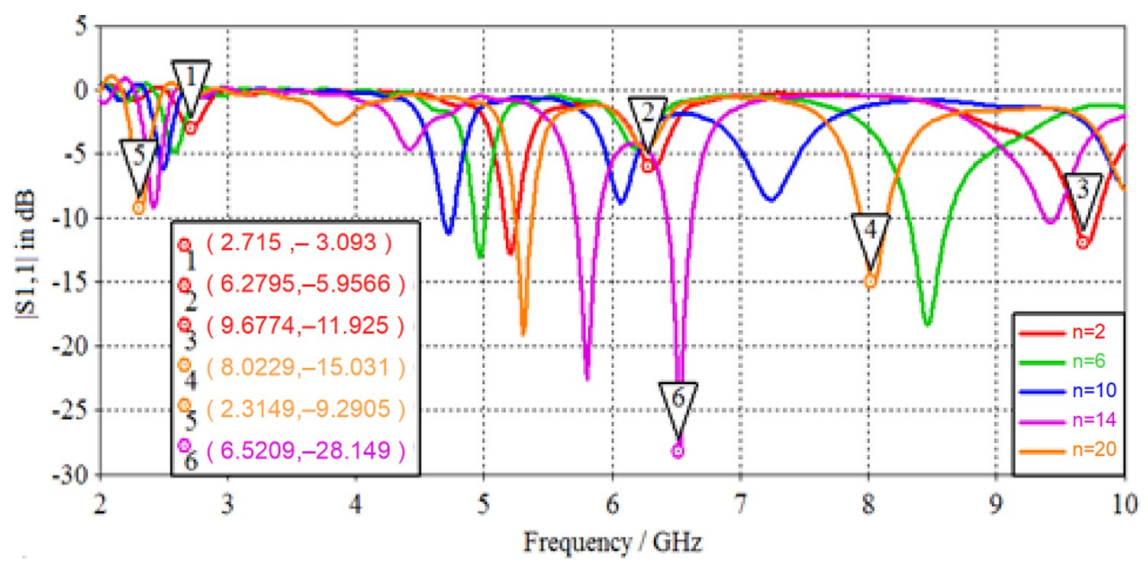

(a) EFFECTS OF LINE LENGTH ON THE RESONANT BANDS

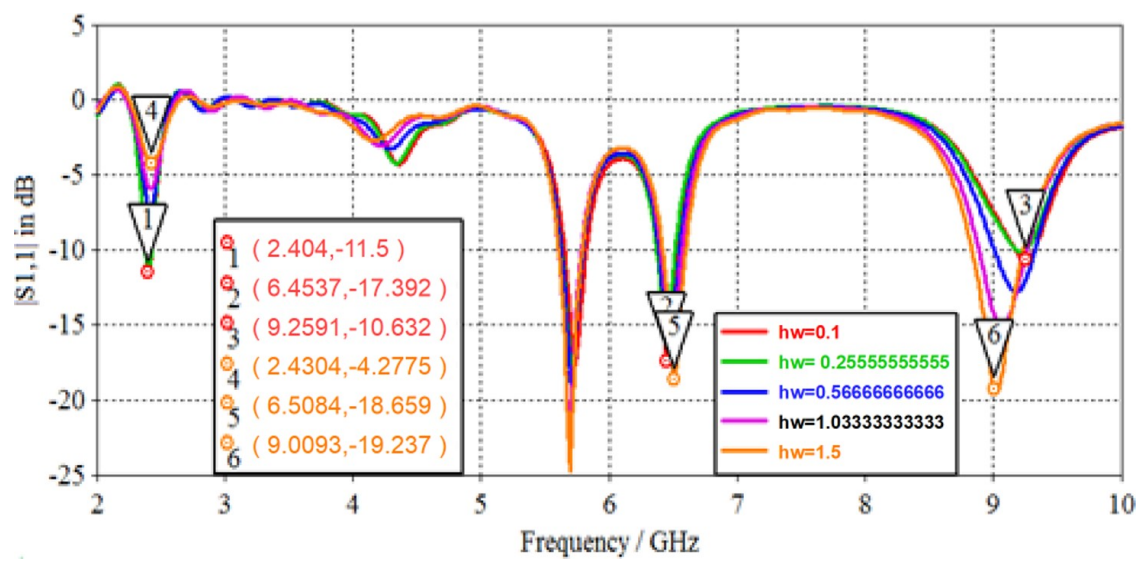

(b) EFFECTS OF LINE WIDTH ON THE RESONANT BANDS

FIG. 7. VARIATIONS OF RESONANT FREQUENCY BANDS WITH RESPECT TO DIFFERENT DIMENSIONS OF MICROSTRIP FEED LINE OF PROPOSED FRACTAL PATCH ANTENNA

Mehran University Research Journal of Engineering \& Technology, Volume 38, No. 3, July, 2019 [p-ISSN: 0254-7821, e-ISSN: 2413-7219] 
respectively. Thus the impedance matching of the three resonances in $\mathrm{C}$ and $\mathrm{X}$ frequency bands are improved upon increasing the microstrip feed line width whereas the frequency resonance of the $\mathrm{X}$ band is shifted downwards.

Increasing line width improves the impedance matching of the $\mathrm{C}$ and $\mathrm{X}$ bands, on the other hand degradation in the impedance matching of the $\mathrm{S}$ band is observed upon increasing the line width. Hence value of line width around $0.3 \mathrm{~mm}$ is selected for optimum BW and radiation characteristics of diagonal slot embedded Triangular Gasket fractal patch radiator.

Detailed dimensions drawing of the Triangular Gasket fractal radiator is illustrated in Fig. 8. Area of triangular patch antenna with length of each side of $67.34 \mathrm{~mm}$ is calculated to be $1963.9 \mathrm{~mm}^{2}$ and area of third order diagonal slot embedded Triangular Gasket fractal antenna with each length of $45.01 \mathrm{~mm}$ as shown in Fig. 8, is calculated to be 877.36 and $378.06 \mathrm{~mm}^{2}$ with correlation to radiating element and copper cladding remaining respectively. Thus there is a $55.32 \%$ size reduction in correspondence to radiating element and $80.74 \%$ in relation with copper cladding remaining of radiating element of the diagonal slot embedded third order fractalized patch in comparison to the triangular patch radiator. Details of the dimensions of third order diagonal slot embedded Triangular Gasket fractal antenna are described in Table 1.

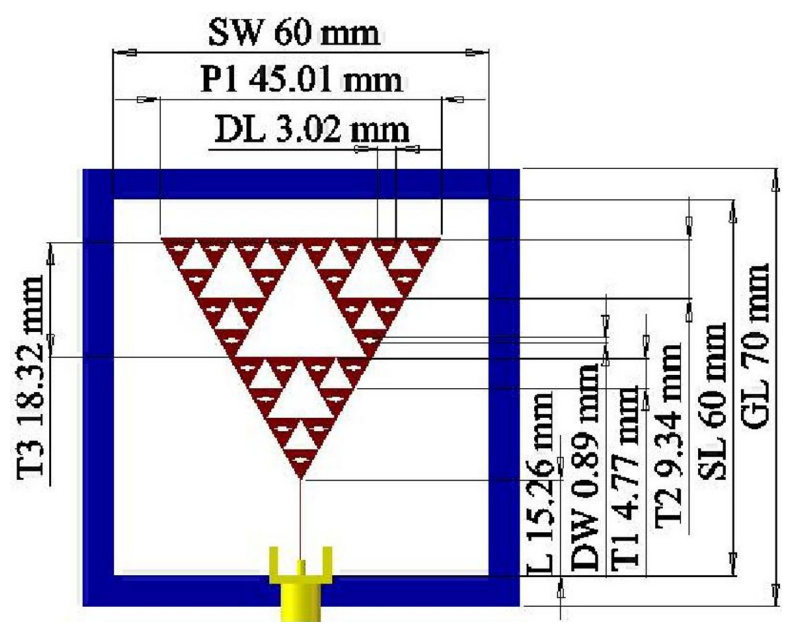

FIG. 8. THIRD ORDER SLOT EMBEDDED TRIANGULAR GASKET FRACTAL PATCH ANTENNA DIMENSIONS TOP VIEW

TABLE 1. DIAGONAL SLOT EMBEDDED TRIANGULAR GASKET FRACTAL PATCH ANTENNA DIMENSIONS DETAILS

\begin{tabular}{|c|c|c|}
\hline Label & Description & Dimensions (mm) \\
\hline SW & Substrate Width & 60.00 \\
\hline SL & Substrate Length & 00.00 \\
\hline T1 & Third order triangle length & 09.34 \\
\hline T2 & Second order triangle length & 18.32 \\
\hline T3 & First order triangle length & 15.26 \\
\hline L & Transmission Line Length & 00.89 \\
\hline DW & Width of diagonal slot & 03.02 \\
\hline DL & Length of diagonal slot & 45.01 \\
\hline P1 & Overall Length & 70.00 \\
\hline GL & Ground Plane Length & \\
\hline
\end{tabular}

Mehran University Research Journal of Engineering \& Technology, Volume 38, No. 3, July, 2019 [p-ISSN: 0254-7821, e-ISSN: 2413-7219] 
For a conducting plane $\mathrm{S}$, the excitation is provided by the electromagnetic fields comprising the Electric and Magnetic field components denoted by $\mathrm{E}$ and $\mathrm{H}$ respectively. Combination of current densities on surface $\mathrm{S}$ will be representing the total current density, denoted by $\mathrm{j}$ [20]. The boundary conditions are represented as:

$$
\vec{n}\left(M_{0}\right) \times \lim _{M \rightarrow M_{0}} \vec{E}(M)=-\vec{n}\left(M_{0}\right) \times \vec{E}\left(M_{0}\right) \quad M_{0} \in S
$$

The basic equation of the integral representation of the required electric field is formulated as:

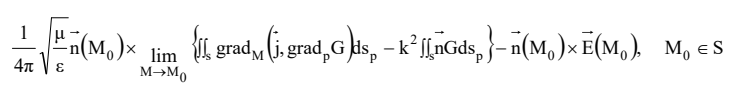

Where

$$
\mathrm{G}=\frac{\exp ^{[-\mathrm{ikR}(\mathrm{M}, \mathrm{P})]}}{\mathrm{KR}(\mathrm{M}, \mathrm{P})}
$$

Is the Green's Function and $\mathrm{R}$ is the distance from the observation point $\mathrm{M}$ to the source point $\mathrm{P}$. This equation is similar to the hypersingular integral Equation (4).

$$
\frac{\mathrm{i}}{4 \mathrm{i} \pi \mathrm{i} \pi} \overrightarrow{\mathrm{n}} \times\left[\iint_{\mathrm{S}}(\overrightarrow{\mathrm{j}} . \nabla) \nabla \mathrm{Gds}+\mathrm{k}^{2} \iint_{\mathrm{S}} \mathrm{j} \mathrm{Gds}\right]=\overrightarrow{\mathrm{n}} \times \overrightarrow{\mathrm{E}}
$$

where $\varepsilon$ is the dilectric constant of the material used for propagation of electromagnetic fields and $\omega$ is the angular frequency representing the operational frequency of the wave propagation and $K$ is the propagation constant.

\section{MEASURED AND SIMULATED RESULTS}

The Triangular Gasket radiator 3D modeling, structure simulation and parameter optimization is done on Ansoft HFSS and CST Microwave Studio. The fabricated prototype of the third order diagonal slot embedded Triangular Gasket fractal patch antenna is illustrated in Fig. 9, where substrate used is FR4 is used as the substrate with loss tangent of 0.02 , dielectric constant of 4.4 and substrate thickness of $1.5 \mathrm{~mm}$, along with aluminum ground plane whose separation with the microstrip proposed fractal patch radiator is optimized for achieving desired frequency responses in S, C and X frequency bands.

The measured and simulated frequency response comparison of the slot embedded third order fractal patch radiator configuration is shown in Fig. 10. It can be seen from the frequency responses that the first frequency resonances for the simulated and fabricated structures is at 2.405 and $2.3775 \mathrm{GHz}$ respectively with the simulated impedance $\mathrm{BW}$ for $\mathrm{S}_{11}$ less than $-10 \mathrm{~dB}$ is 2.358 to 2.3822 $\mathrm{GHz}$. $\mathrm{C}$ band frequency resonances are centered on 5.712 $\mathrm{GHz}$ at $-18.33 \mathrm{~dB}$ and $6.45 \mathrm{GHz}$ respectively and BWs corresponding frequency points of the $\mathrm{C}$ band for $\mathrm{S}_{11}<-$ $10 \mathrm{~dB}$ are 5.631-5.793 GHz and 6.373-6.522 GHz respectively.

Measured impedance BW for two frequency points in C Band are centered at 5.577 and $6.33 \mathrm{GHz}$ with $\mathrm{BW}$ of $\mathrm{S}_{11}$ less than $-10 \mathrm{~dB}$ from $5.50-5.65$ and $6.28-6.37 \mathrm{GHz}$ respectively. Simulated $\mathrm{X}$ band frequency response is centered on $9.208 \mathrm{GHz}$ at $-10.41 \mathrm{~dB}$ with the impedance BW of $\mathrm{S}_{11}<-10 \mathrm{~dB}$ of 9.14-9.27 GHz, while the measured impedance $\mathrm{BW}$ for the $\mathrm{X}$ band frequency response is $\mathrm{S}_{11}<-10 \mathrm{~dB}$ of $8.72-8.994 \mathrm{GHz}$ centered on $8.84 \mathrm{GHz}$ at

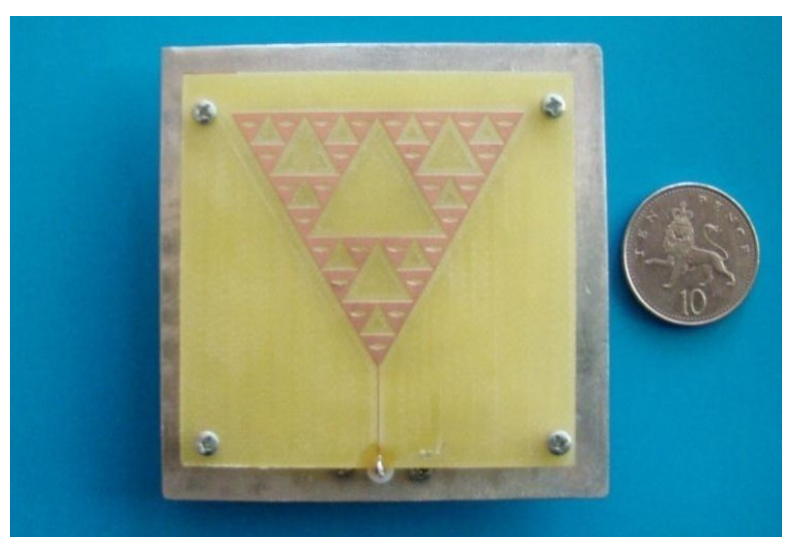

FIG. 9. FABRICATED PROTOTYPE OF THIRD ORDER SLOT EMBEDDED TRIANGULAR GASKET FRACTAL MICROSTRIP PATCH ANTENNA

Mehran University Research Journal of Engineering \& Technology, Volume 38, No. 3, July, 2019 [p-ISSN: 0254-7821, e-ISSN: 2413-7219] 
$-13.032 \mathrm{~dB}$. Thus the diagonal slot embedded Triangular Gasket fractal radiator is operating with first resonant point in $\mathrm{S}$ band frequency range, second and third resonant points in $\mathrm{C}$ band frequency range and fourth resonant point in $\mathrm{X}$ band. Simulated CST 3D radiation plots are illustrated in Fig. 11 and simulated vs measured 2D radiation plots are shown in Fig. 12.

Gain plots shown in Figs. 11-12 for the three frequency bands are well shaped, providing suitable use of the antenna for WiFi and WLAN applications. Current density, H-field, E- Field and surface current plots for the three frequencies of S, C and $\mathrm{X}$ bands are demonstrated in Fig. 13. The current flow is along $y$-axis where the Efields for $2.41 \mathrm{GHz}$ is illustrated in Fig. 13(a), signifying the resonance due to the maximum length of the radiator. The E-fields at 6.5 GHz in C band is shown in Fig. 13(b), where the second order scaled down diagonal slots and triangles are radiating signifying the resonances in the second band of slot embedded fractal radiator. E-fields at resonant frequency of 9.23 GHz is depicted in Fig. 13(c), where it can be seen that the individual unit cell diagonal slot embedded triangles are radiating producing the resonance in the $\mathrm{X}$ band. The $\mathrm{X}$-component of the $\mathrm{H}$ fields and surface currents of slot embedded fractal patch radiator are demonstrated in Fig. 13(d-i) for the frequencies of $2.41,6.5$ and $9.23 \mathrm{GHz}$.

Whereas the whole antenna, second order diagonal slot embedded triangles and third order small diagonal slot embedded triangles are radiating respectively for producing the desired resonances. The current density plot for $2.41 \mathrm{GHz}$ is shown in Fig. 13(j) with the current concentration on the proposed fractal radiating antenna as a whole with no radiations in the inner and outer sides of the antenna signifying the radiations due to the maximum length of radiating antenna and responsible for the radiations in first resonance band. For the second resonating frequency of $5.73 \mathrm{GHz}$, the current is concentrated in the second order diagonal slot triangles of the proposed geometry with little currents flowing in the middle and outer regions of the second order diagonal slot embedded triangles as shown in Fig. 13(k) and no currents concentrated in the middle of the proposed fractal patch antenna. Current density of the slot embedded Triangular Gasket fractal radiating antenna for the third resonant frequency of $9.3 \mathrm{GHz}$ is shown in Fig. 13(1), with strong concentration of current in the inner and outer regions of the third order diagonal slot embedded triangles, hence producing resonance in the $\mathrm{X}$ band frequency range.

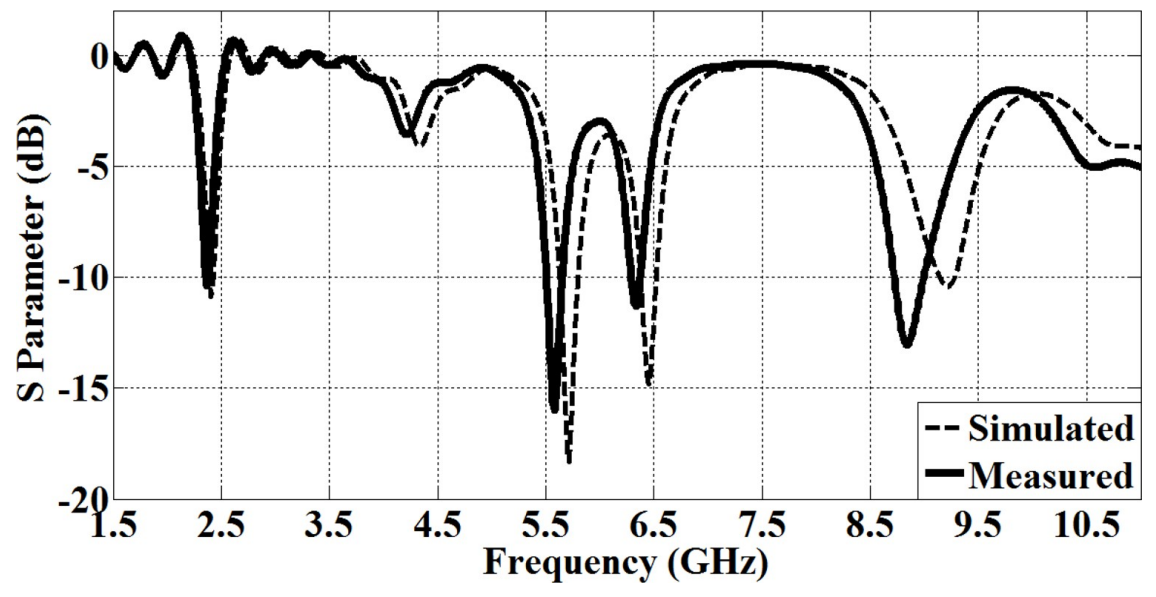

FIG. 10. MEASURED AND SIMULATED $S_{1 I}$ RESPONSES OF THIRD ORDER SLOT EMBEDDED TRIANGULAR GASKET FRACTAL PATCH ANTENNA

Mehran University Research Journal of Engineering \& Technology, Volume 38, No. 3, July, 2019 [p-ISSN: 0254-7821, e-ISSN: 2413-7219] 


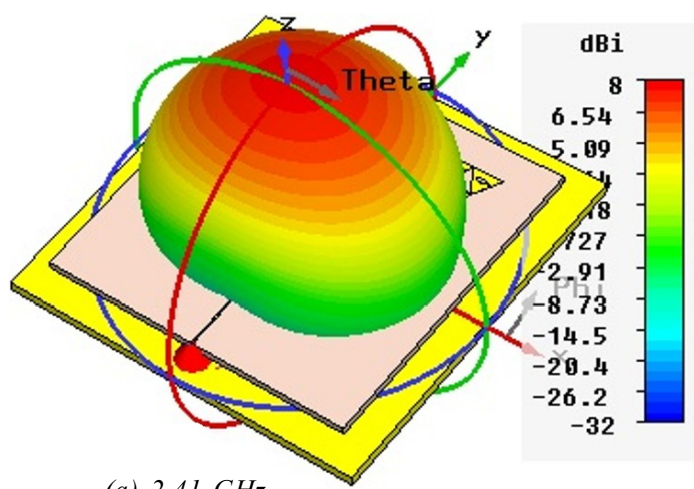

(a) $2.41 \mathrm{GHz}$
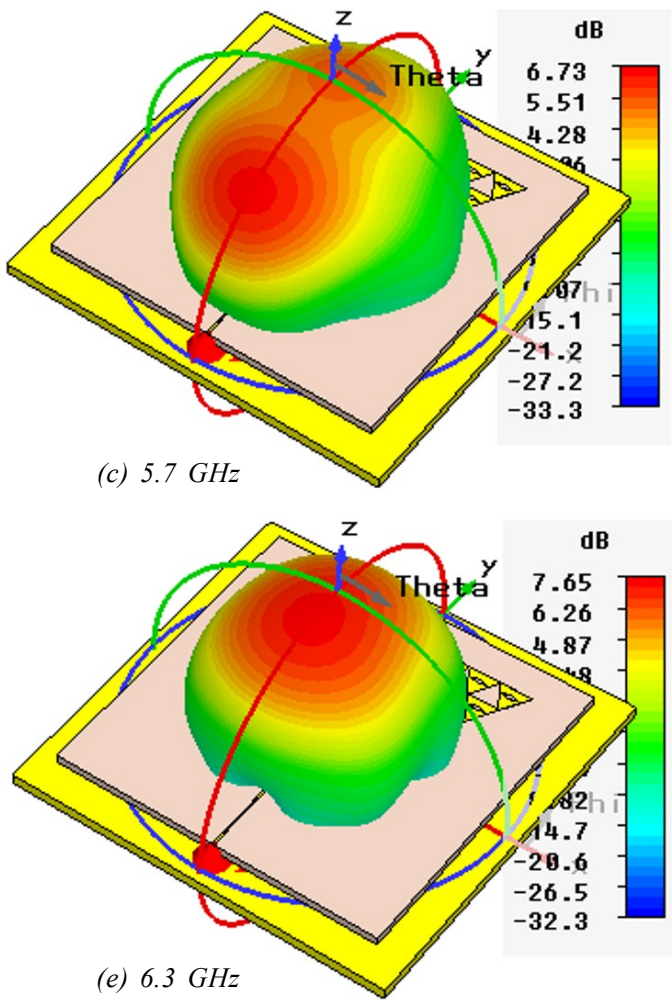

(e) $6.3 \mathrm{GHz}$

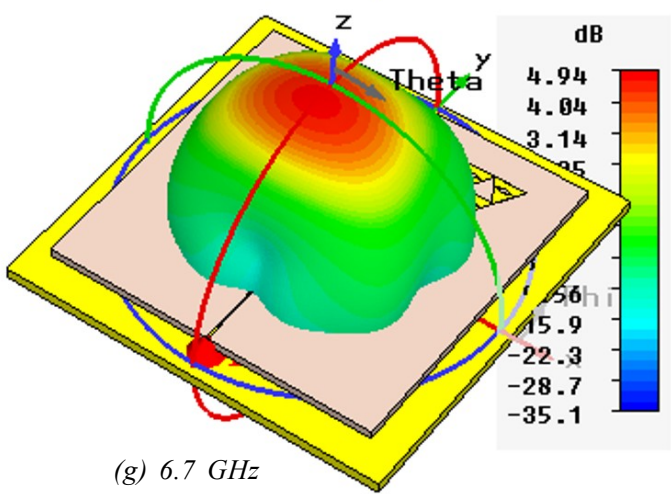

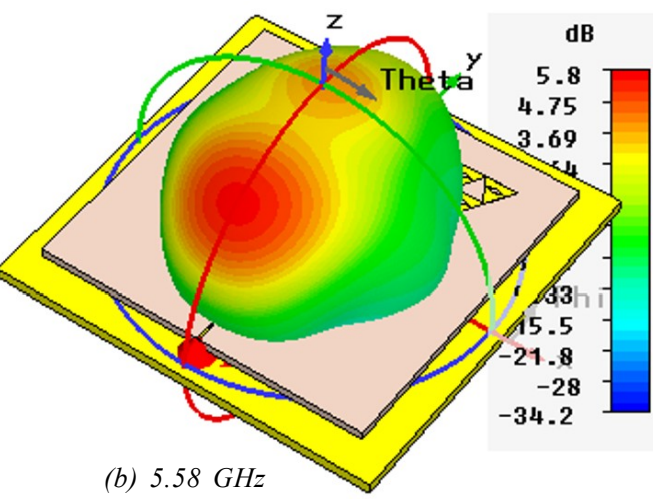

dB
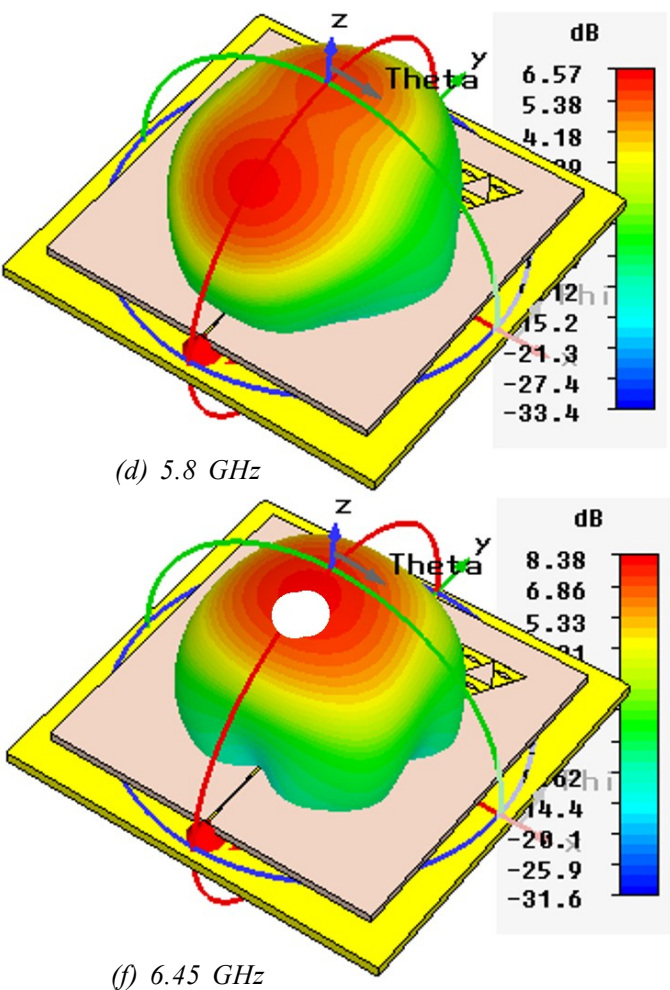

(f) $6.45 \mathrm{GHz}$

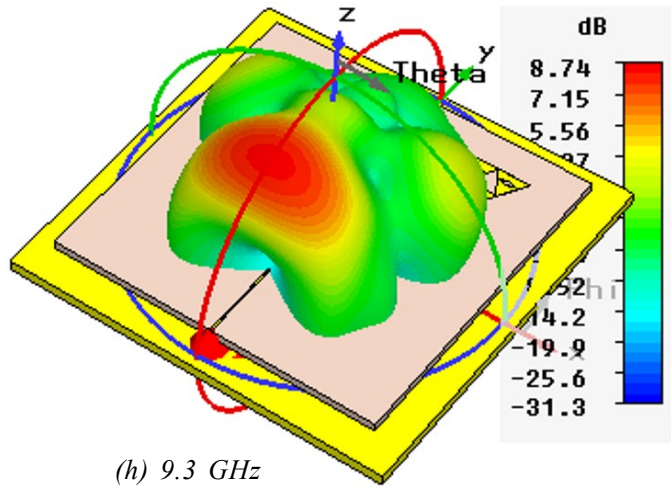

FIG. 11. CST GAIN PLOTS OF PROPOSED THIRD ORDER SLOT EMBEDDED TRIANGULAR GASKET FRACTAL PATCH ANTENNA AT FREQUENCIES

Mehran University Research Journal of Engineering \& Technology, Volume 38, No. 3, July, 2019 [p-ISSN: 0254-7821, e-ISSN: 2413-7219] 

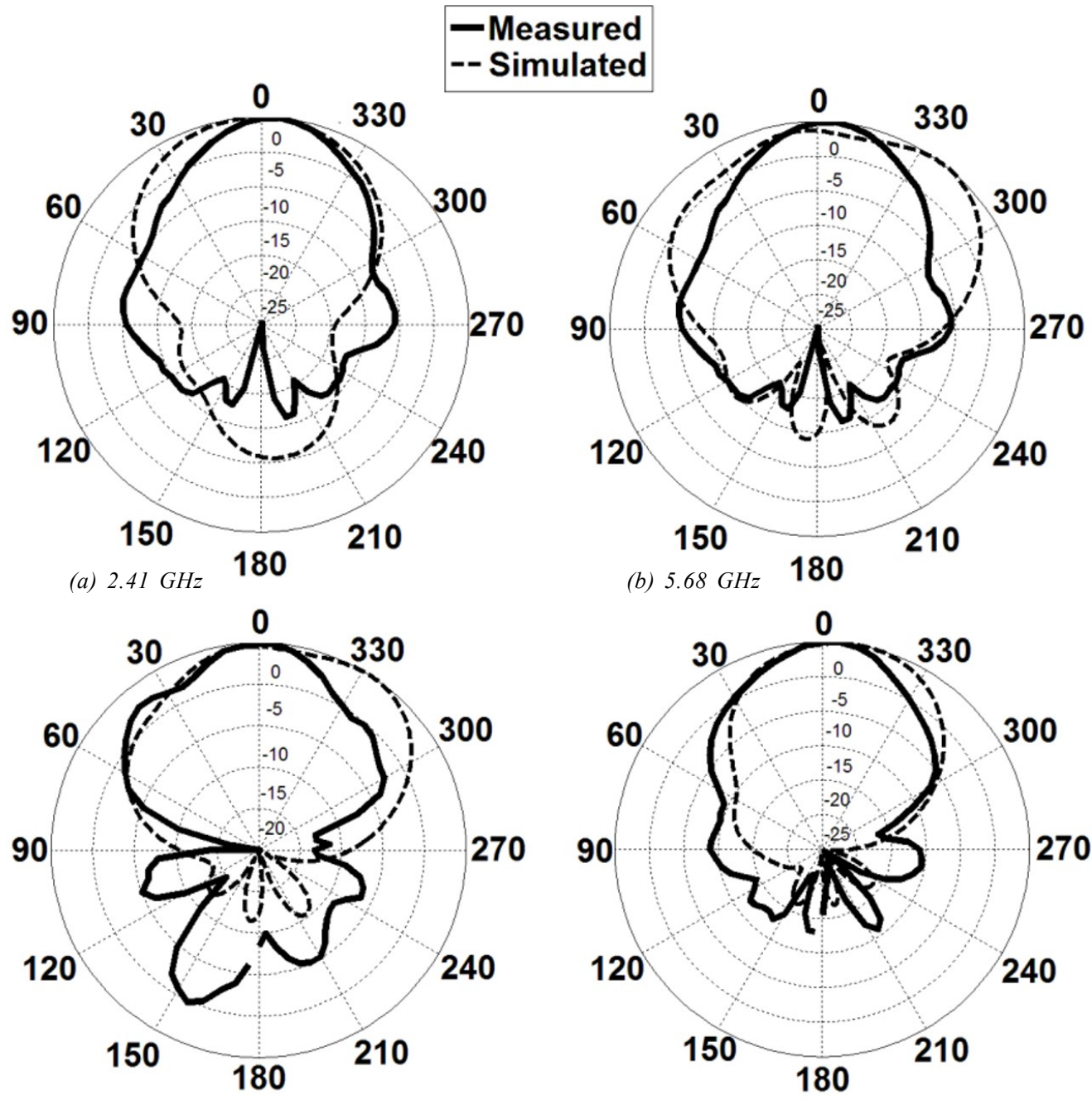

(c) $5.85 \mathrm{GHz}$

(d) $6.3 \mathrm{GHz}$
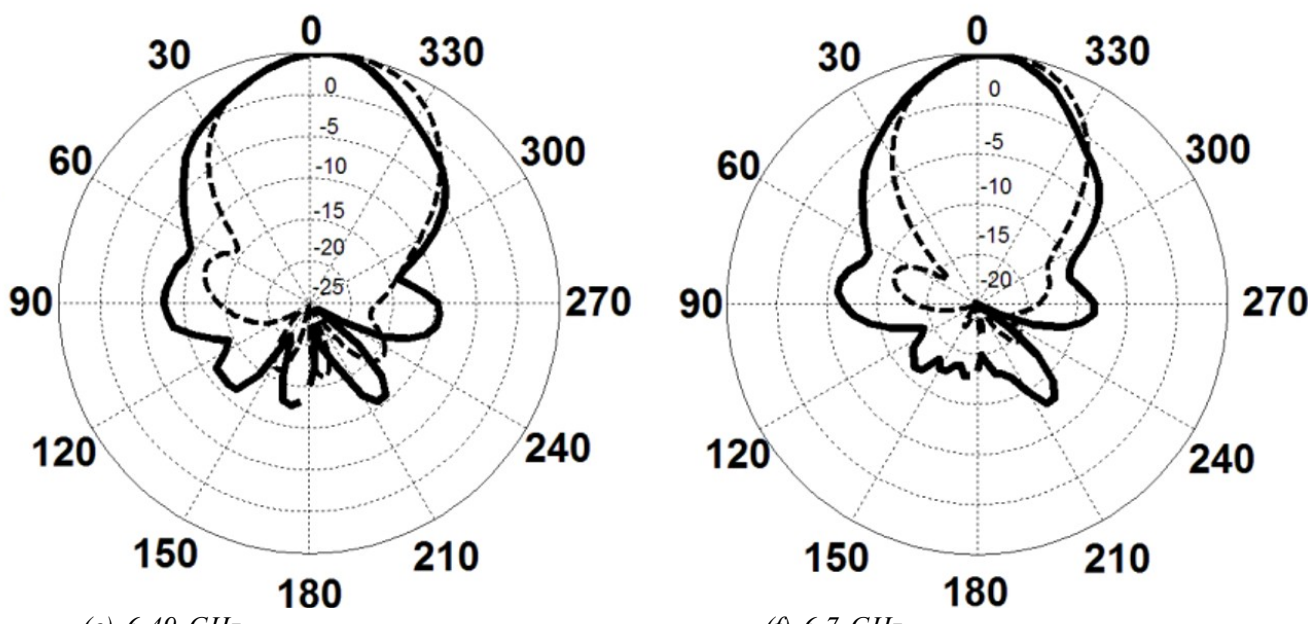

FIG. 12. MEASURED VS SIMULATION GAIN PLOTS FOR THE THIRD ORDER DIAMOND SIERPINSKI FRACTAL PATCH ANTENNA AT FREQUENCIES

Mehran University Research Journal of Engineering \& Technology, Volume 38, No. 3, July, 2019 [p-ISSN: 0254-7821, e-ISSN: 2413-7219] 


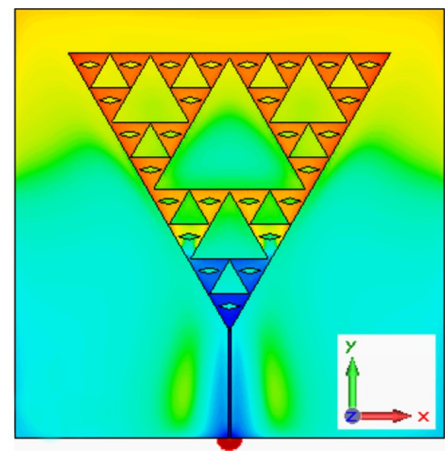

(a) 2.41

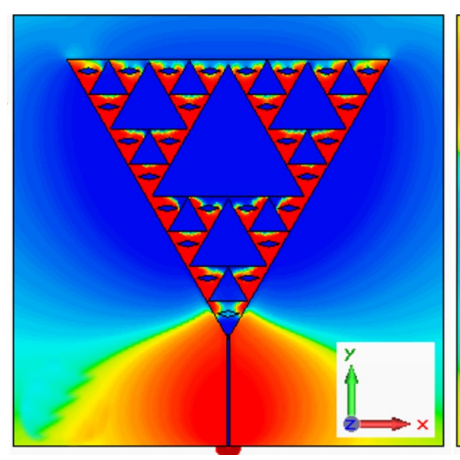

(d) 2.41

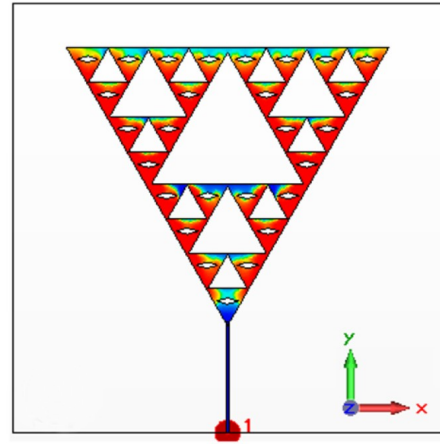

(g) 2.41

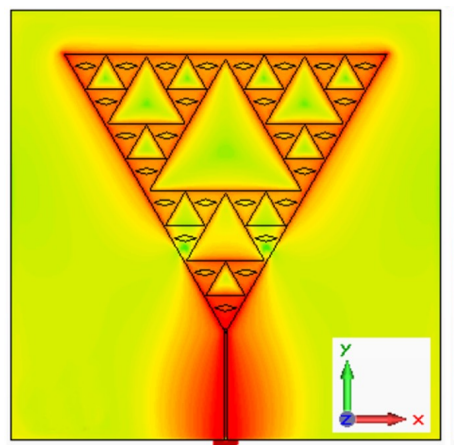

(j) 2.41

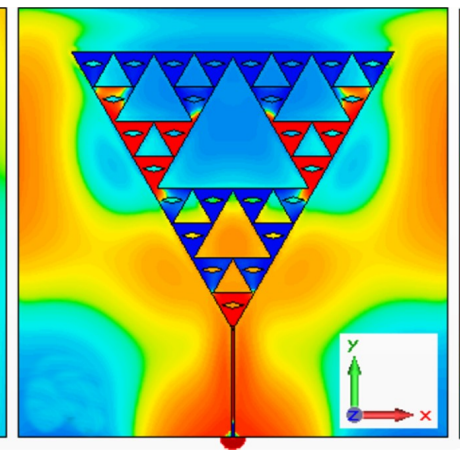

(b) 6.5

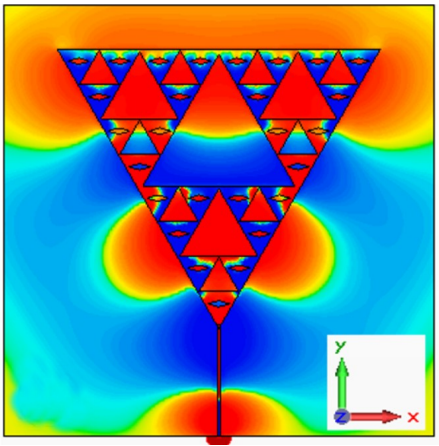

(e) 6.5

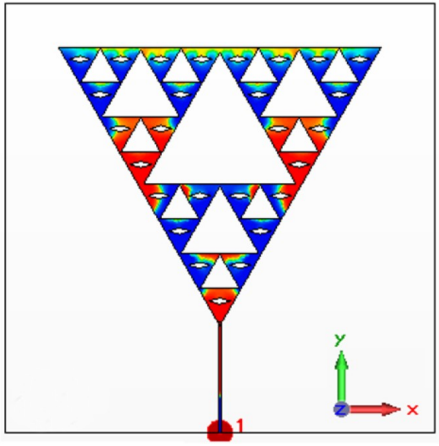

(h) 6.5

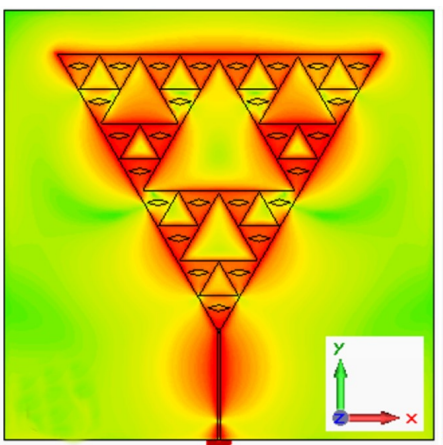

(k) 6.5

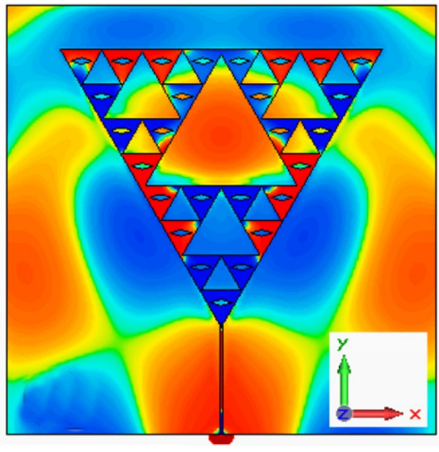

(c) $9.23 \mathrm{GHz}$; H-FIELDS

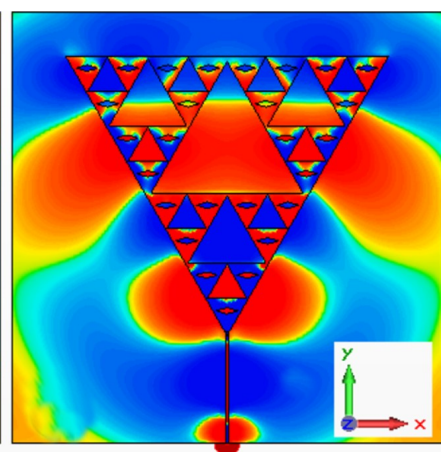

(f) $9.23 \mathrm{GHz}$; SURFACE CURRENTS

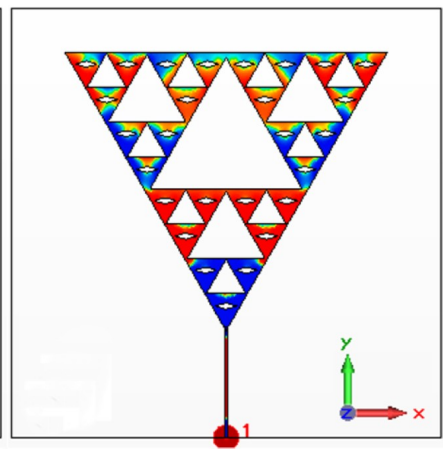

(i) $9.23 \mathrm{GHz}$; CURRENT DENSITIES

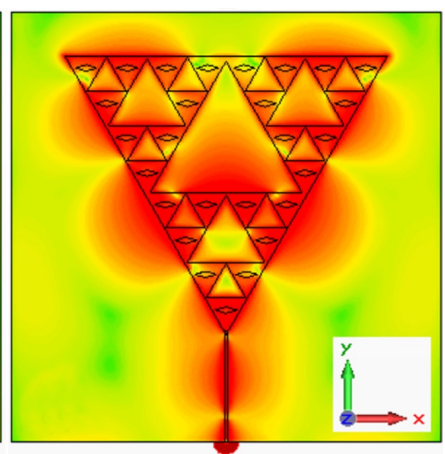

(l) $9.23 \mathrm{GHz}$

FIG. 13. CST PATTERN DISTRIBUTIONS FOR THE DIAGONAL SLOT EMBEDDED TRIANGULAR GASKET FRACTAL PATCH RADIATOR; E-FIELDS

Mehran University Research Journal of Engineering \& Technology, Volume 38, No. 3, July, 2019 [p-ISSN: 0254-7821, e-ISSN: 2413-7219] 


\section{CONCLUSION}

A novel diagonal slot embedded Triangular Gasket fractal antenna of the third order is designed for operation in S, C and $\mathrm{X}$ band frequencies for wireless applications. Effects of embedding different dimensions of diagonal slot geometries are analyzed and optimal values are selected for the proposed fractal antenna. Significant size reduction is achieved along with multiband behavior by using the proposed fractal geometry. Parametric analysis in correlation with various microstrip feed line dimensions and ground plane separation from the slot embedded fractal patch radiator is performed for achieving optimized desired frequency bands for efficient BW and antenna radiation characteristics. E-Fields and current distributions are analyzed for different resonant bands of the proposed antenna. Proposed slot embedded Triangular Gasket fractal patch radiator is simulated, optimized, fabricated and tested for desired frequency bands of operation.

\section{ACKNOWLEDGEMENT}

Authors would like to acknowledge Prof. Omar Masood Khan, and Syed Shiraz Mohani, Assistant Professor, Department of Faculty of Engineering Sciences and Technology, Iqra University, Karachi, Pakistan, for invaluable discussions and feedback.

\section{REFERENCES}

[1] Kiran, D.V., Sankaranarayanan, D., and Mukherjee, B., "Compact Embedded Dual-Element Rectangular Dielectric Resonator Antenna Combining Sierpinski and Minkowski Fractals", IEEE Transaction on Components, Packaging and Manufacturing Technology, Volume 7, No. 5, pp. 1281-1291, May, 2017.

[2] Yang, X., Liu, Y., Xu, Y., and Gong, S., "Isolation Enhancement in Patch Antenna Array with Fractal UCEBG Structure and Cross Slot”, IEEE Antennas and Wireless Propagation Letters, Volume 16, pp. 2175-2178, May, 2017.
[3] Singhal, S., and Singh, A.K., "CPW-fed Hexagonal Sierpinski Superwideband Fractal Antenna", IET Microwaves, Antennas \& Propagation, Volume 10, No. 15, pp. 1701-1707, December, 2016.

[4] Wang, R., Wang, B.Z., Gong, Z.S., and Ding, X., "Compact Multiport Antenna With Radiator-Sharing Approach and Its Performance Evaluation of Time Reversal in an Intra-Car Environment", IEEE Transactions on Antennas and Propagation, Volume 63, No. 9, pp. 4213-4219, September, 2015.

[5] Zahed, A., El-Hag, A.H., and Qaddoumi, N., "Comparison of Different Fourth Order Hilbert Fractal Antennas for Partial Discharge Measurement”, IEEE Transaction on Dielectrics and Electrical Insulation, Volume 24, No. 1, pp. 175-182, February, 2017.

[6] Borja, C., and Romeu, J., "On the Behavior of Koch Island Fractal Boundary Microstrip Patch Antenna", IEEE Transactions on Antennas and Propagation, Volume 51, No. 6, pp. 1281-1291, June, 2003.

[7] Kgwadi, M., and Drysdale, T.D., "Diode-Switched Thermal-Transfer Printed Antenna on Flexible Substrate", Electronic Letters, Volume 52, No. 4, pp. 258-260, Feburary, 2016.

[8] Anguera, J., Martinez, E., Puente, C., Borja, C., and Solder, J., "Broad-Band Dual-Frequency Microstrip Patch Antenna With Modified Sierpinski Fractal Geometry", IEEE Transactions on Antennas and Propagation, Volume 52, No. 1, pp. 66-73, January, 2004.

[9] Song, C.T.P., Hall, P.S., and Shiraz, H.G., "Perturbed Sierpinski Multiband Fractal Antenna with Improved Feeding Technique”, IEEE Transactions on Antennas and Propagation, Volume 51, No.5, pp. 1011-1017, May, 2003.

[10] Khan, O.M., Islam, Z.U., Rashid, I., Bhatti, F.A., and Islam, Q.U.,"Novel Miniaturized Koch Pentagonal Fractal Antenna for Multiband Wireless Applications", Progress in Electromagnetics Research, Volume 141, pp. 693-710, 2013. 
[11] Liu, H., Liu, Y., Wei, M., and Gong, S., "Dual-Broadband Dielectric Resonator Antenna Based on Modified Sierpinski Fractal Geometry", Electronic Letters, Volume 51, No. 11, pp. 806-808, May, 2015.

[12] Ooi, B.L., “A Modified Contour Integral Analysis for Sierpinski Fractal Carpet Antennas with and Without Electromagnetic Band Gap Ground Plane”, IEEE Transactions on Antennas and Propagation, Volume 52, No. 5, pp. 1286-1293, May, 2004.

[13] Oraizi, H., and Hedayati, S., "Circularly Polarized Multiband Microstrip Antenna Using the Square and Giuseppe Peano Fractals", IEEE Transactions on Antennas and Propagation, Volume 60, No. 7, pp. 3466-3470, July, 2012.

[14] Romeu, J., and Soler, J., "Generalized Sierpinski Fractal Multiband Antenna”, IEEE Transactions on Antennas and Propagation, Volume 49, No. 8, pp. 1237-1239, August, 2001.

[15] Taghadosi, M., Albasha, L., Qaddoumi, N., and Ali, M., "Miniaturised Printed Elliptical Nested Fractal Multiband Antenna for Energy Harvesting Applications", IET Microwave, Antennas and Propagation, Volume 9, No. 10, pp. 1045-1053, July, 2015.
[16] Chaimool, S., Chokchai, C., and Akkaraekthalin, P., "Multiband Loaded Fractal Loop Monopole Antenna for USB Dongle Applications", Electronic Letters, Volume 48, No. 23, November, 2012.

[17] Kim, H.B., and Hwang, K.C., "Dual-Port Spidron Fractal Slot Antenna for Multiband Gap-Filler Applications", IEEE Transactions on Antennas and Propagation, Volume 60, No. 10, pp. 4940-4943, October, 2012.

[18] Bayatmaku, N., Lotfi, P., Azarmanesh, M., and Soltani, S., "Design of Simple Multiband Patch Antenna for Mobile Communication Applications Using New E-Shape Fractal", IEEE Antennas and Wireless Propagation Letters, Volume 10, pp. 873-875, 2011.

[19] Mehdipour, A., Rosca, I.D., Sebak, A.R., Trueman, C.W., and Hoa, S.V., "Full-Composite Fractal Antenna Using Carbon Nanotubes for Multiband Wireless Applications", IEEE Antennas and Wireless Propagation Letters, Volume 9, pp. 891-894, 2010.

[20] Potapov, A.A., Matveev, E.N., Potapov, V.A., and Laktyunkin, A.V., "Mathematical and Physics Modelling of Fractal Antennas and Fractal Frequency Selective Surfaces and Volumes for the Fractal Radio Systems", European Conference on Antennas and Propagation, pp. 1-6, November, 2007. 